\title{
Mobile learning and initial teacher education
}

\author{
R. Wood \\ School of Education, Kingston University, UK
}

\begin{abstract}
The advent of third generation phones and the prospect of increased speed in data transfer have developed further opportunities for both learners and teachers to meet together, access and exchange information in virtual spaces whilst on the move.

As part of a small pilot study, the potential for third generation smart phones to enhance teaching and learning processes is currently being analysed and evaluated. Five lecturers within the School of Education are each documenting their use and experience of such devices with particular focus upon the role of the teacher in designing, managing and evaluating potential learning opportunities. Prior to purchasing mobile phones, the lecturers engaged in discussion surrounding the range of features and their potential to support teaching and learning activities. Furthermore, during the initiation of this project, discussions surrounding the use of mobile phone technology within initial teacher education prompted further questions surrounding the professionality of teachers and the nature of professional development.

This paper will therefore reflect upon a developing understanding of professional practice in light of mobile learning opportunities and consider the theoretical perspectives and rationale surrounding the decisions to pilot such a project.
\end{abstract}

Keywords: mobile phones, pedagogy, networks, communities of practice, multimedia, education professional.

\section{Introduction}

The School of Education at Kingston University offers one year full-time postgraduate and three year full-time undergraduate programmes which aim to prepare students to teach in either the secondary or the primary school context. During the course of their studies students enrolled on the postgraduate 
certificate in primary education programme are required to spend 90 days working in primary schools in order to develop their expertise and understanding as a class teacher. School placements extend over a large geographical area surrounding Kingston University and are undertaken in two main blocks: one in the autumn term and the other bridging the spring and summer term. For the remainder of the academic year, the students attend taught programmes at the university.

Whilst on school experience the students remain in contact with the university through visits from a liaison tutor; those who have a university-trained schoolbased mentor receive biweekly visits from the liaison tutor whilst those who have no designated school-based mentor will be visited by the liaison tutor on a weekly basis. Access to a virtual learning environment provides additional opportunities for students and tutors to remain in contact by reducing the constraints associated with time and distance Preece [1]. Here they may view announcements and locate information through access to the World Wide Web from a computer terminal. Asynchronous communication by way of a discussion board offers formal opportunities for students to engage in electronic discourse surrounding their school experience with fellow students and university tutors. Comments, questions and ensuing discussions are developed over a period of time with tutors and students making contributions whenever they are able to access the virtual learning environment. E-mail forms another avenue of communication for the students with messages sent to other students or to tutors at the School of Education.

Over the past few years mobile phones have played an increasingly important role in maintaining communication links between university tutors and students within the context of school experience. Friendship groups which emerge whilst the students are attending the taught programme provide an informal support network which remains intact during school placements. Whilst the virtual learning environment provides some opportunity for students to engage in discussion surrounding their understanding of pedagogic practice mobile phones have facilitated informal support networks by building upon natural contact within and between friendship groups. Such mechanisms for communication offer vital support during extended school experience placements. A further step has therefore been to enhance the virtual learning environment by evaluating the flexibility offered by mobile phone networks.

This project was initiated following observations made during successive years of working on the primary PGCE information and communications technology module. The study aimed to investigate the potential for mobile technologies to support teaching and learning in the specific context of initial teacher education and was supported with funds received from a teaching fellowship award. Initially, a working group of five lecturers within the School of Education was established where discussions focussed upon the ways in which such devices may support and enhance teaching and learning opportunities. The lecturers concerned were selected because of their involvement in the design, delivery and management of the primary PGCE programme. 


\section{The professional role of the teacher}

In what may be described as a challenging role, the teacher professional is faced with a multiplicity of demands. Schon [2] suggests that "complexity, uncertainty, instability, uniqueness and value conflicts are increasingly perceived as central to the world of professional practice.' In attempting to manage a progressively more complex education system influenced by society's demands the role of the teacher has, and will continue to be, constantly reshaped and redefined. The teacher therefore requires the ability to adapt, change and develop a broader spectrum of skills in order to respond to these demands which are largely driven by advances in microelectronics and telecommunications.

As a technological paradigm, the term 'informationalism' has been applied to encompass the many facets and capability of current and developing microelectronics-based information technology Castells [3]. Such a paradigm is indicative of our society with networking between individuals and groups being one of its distinctive features. Opportunities to communicate and transfer data to one another exist through mechanisms such as synchronous or real-time communication systems (internet relay chat, videoconferencing, telephone, text and multimedia messaging) and asynchronous systems (bulletin boards, newsgroups) where interactions are generated over minutes or months. Digital networks have created opportunities for a connected society on a global scale (Castells [3]).

Technological imperatives demand new levels of pedagogic expertise. Individuals are required to operate successfully within a society overflowing with data. Such data may be presented, accessed and transferred through an everchanging range of digital technologies. The advent of new technologies also brings uncertainty to the working life of an individual. The lifelong career is giving way to the concept of lifelong learning where the employability of an individual requires flexibility and adaptability in order to retrain and actively seek out opportunities to gain the necessary skills, knowledge and understanding associated with necessary changes in employment Hargreaves [4]. Currently, the rhetoric of educational reform as evidenced in documents such as the Department for Education and Skill's Five Year Strategy for Children and Learners [5] places emphasis upon being 'employable for life' as opposed to having a 'job for life' and the development of a 'knowledge society' where knowledge workers are the vital ingredient in a knowledge-based economy. Education must therefore maintain momentum in order to generate a 'flexible, multi-skilled worker, and that worker in turn must be ready to become a 'lifelong learner'.' Moore [6] Preparing individuals to live and work in such times may be viewed as fundamental to society itself and the ability of educators to respond appropriately is critical.

Some time ago, the influential work of Hoyle [7] introduced the term 'professionality' to describe the 'knowledge, skills and procedures employed by teachers in the process of teaching.' Conventional methods of professional development such as in-service training (INSET) days or cascade models did not allow sufficient adaptability and flexibility in increasingly fast-changing times. 
Whole school INSET sessions have been few and far between. Supply cover for individual teachers remains expensive in terms of the limited school budget and potentially disruptive for a class of children. Such factors have inhibited the successful development of teachers on a continuous and wide-ranging basis.

However, more recently, there has been consideration with regards the way in which the professionality of teachers and prospective teachers may respond dynamically to allow acquisition of new skills, knowledge and understanding associated with professional expertise. It may also be argued that a circular conundrum exists where in order to respond rapidly and advance with technological developments the teaching profession may need to utilise technology itself. The acquisition and use of leading edge technology, for example smartphones and mobile communications networks, may be regarded as a prime ingredient of models of professionalism and professional learning endorsed by Government initiatives. The challenge which therefore faces initial teacher education establishments is how to best prepare students for their professional role within the knowledge society.

\section{Mobile technology}

Mobile technologies may be best defined as those which are 'small enough to fit comfortably into a purse, pocket or holster' Livingston [8] in contrast with portable technologies such as laptop computers which, although mobile, are not as convenient to carry at all times. Mobile phones are one example of mobile technology and have become increasingly diverse in their design with basic models allowing the user to access other individuals by telephone or text whilst on the move. More sophisticated mobile phones offer a greater range of capabilities such as digital camera, sound recording, multimedia messaging and Internet access to name but a few.

Smartphones have combined the functionality of personal digital assistants (PDA's) and mobile phones to allow users access to an electronic personal organiser in addition to telecommunications. As smartphones have become more sophisticated, the ranges of features have increased so that some may include basic software applications such as note-taking, calendar and e-mail clients found on personal computers in addition to multimedia capability. Connectivity to the World Wide Web may be achieved through a Wireless Local Area Network which allows users to access a local area network (LAN). General Packet Radio Service (GPRS) is currently the most widely used technology for high speed data transfer where mobile smartphone networks are concerned. However, as from 2004, third generation (3G) capability phones have become widely available. Third generation capability is a relatively new addition to the repertoire of connectivity options and aims to increase the speed at which data may be transferred from and to the mobile device. This may be viewed as mobile technology's equivalent of broadband with data transfer approaching rates of up to $2.4 \mathrm{Mb} / \mathrm{s}$.

Currently there are two main operating systems concerned with the more sophisticated end of the smartphone market namely Symbian and Windows 
Mobile. PDA operating systems are dominated by PalmOS and Windows Mobile whilst mobile phone manufacturers such as Nokia, Motorola and Ericsson are heavily invested in Symbian systems.

As pointed out by Anderson and Blackwood [9] the mobile technology market is fast moving with continual adaptations and developments in underlying features such as processors, available memory and screen functionality. In a more recent paper, Anderson [10] highlights the growing dominance of Symbian operating systems within the mobile device market with an anticipated increase from 55\% share in the market to a $60 \%$ share by 2009 . As such, the work completed on this paper is a reflection of smartphone technologies available in the latter months of 2005.

Multimedia capability is becoming integrated into mobile phone design with camera, video capture and sound recording/playback included as part of the specification of smartphones today. Developments appear to move the mobile phone closer to a multipurpose device capable of pushing the boundaries created by time and distance in order to create what Anderson and Blackwood describe as 'new opportunities for meaningful interactions between disparate communities' [11].

Although the list is not, by any means extensive, the table 1 highlights some of the data capture, communication and connectivity features which may currently be included in smartphone design. The resulting combination of these features is a multimedia mobile device which may connect through a variety of routes in order to access and transfer media-rich data.

Table 1: $\quad$ Smartphone features.

\begin{tabular}{|l|l|}
\hline \multicolumn{1}{|c|}{ feature } & \multicolumn{1}{c|}{ purpose } \\
\hline GPRS & $\begin{array}{l}\text { standard technology for data enabled mobile network -allows } \\
\text { high speed wireless connectivity to the Internet }\end{array}$ \\
\hline 3G & $\begin{array}{l}\text { More recent data exchange technology which offers greater } \\
\text { speed than the GPRS technology }\end{array}$ \\
\hline Camera & Still digital images may be recorded \\
\hline Video Camera & Moving digital image may be recorded. \\
\hline Sound recording & Useful for recoding voice memos and short interviews. \\
\hline SMS & Text messaging \\
\hline MMS & Multimedia messaging \\
\hline Internet Access & $\begin{array}{l}\text { Web browser used in conjunction with relevant connectivity } \\
\text { e.g. GRPS and 3G. Access to the web allows individuals to } \\
\text { locate, download or upload information }\end{array}$ \\
\hline Wireless connectivity & $\begin{array}{l}\text { Wi-Fi - for example Kingston University provides wireless } \\
\text { access to the Internet by providing wireless access points } \\
\text { across the various campuses }\end{array}$ \\
\hline Bluetooth & $\begin{array}{l}\text { This provides wireless access at a range of approximately 10 } \\
\text { metres between one Bluetooth enabled device and another. The } \\
\text { phone may also act as an external wireless modem for a laptop } \\
\text { through Bluetooth connectivity. }\end{array}$ \\
\hline
\end{tabular}

Clearly, problems may arise when attempting to produce materials which may be accessed by different devices and systems. Content designed for one type of smartphone may not be accessible on another. Files and screen displays may not 
be supported and content therefore unrecognised between devices However the boundaries of mobile technology are constantly being challenged and broken down and it is through accessing and trialling such technologies that this may continue to respond to the demands of society itself.

\section{Student access and use of mobile phones}

At the beginning of each year's primary PGCE programme, a relatively informal survey has provided information regarding student access to technology. Each year there has been a clear increase in the number of students who possess mobile phones and, for the past three years, all but one of the students have indicated that they are owners of this type of technology.

To ascertain the range, diversity and use of such technology by the students, an electronic survey was posted on the University's virtual learning environment in October 2005. From a cohort of 135 students, responses were received from 72 individuals. The results of this survey are summarised in table 2.

Table 2: $\quad$ Mobile phone features available to students.

\begin{tabular}{|l|c|c|c|c|}
\hline \multicolumn{1}{|c|}{ feature } & $\begin{array}{c}\text { Features } \\
\text { present on } \\
\text { phone }\end{array}$ & $\begin{array}{c}\text { Features } \\
\text { used most } \\
\text { often - every } \\
\text { week/ two } \\
\text { weeks }\end{array}$ & $\begin{array}{c}\text { Features } \\
\text { used } \\
\text { infrequently- } \\
\text { every month/ } \\
\text { two months }\end{array}$ & $\begin{array}{c}\text { Features } \\
\text { never used }\end{array}$ \\
\hline Text (SMS) & 72 & 72 & 0 & 0 \\
\hline Multimedia messaging (MMS) & 57 & 12 & 23 & 22 \\
\hline Video Capture & 51 & 7 & 29 & 15 \\
\hline Still digital photograph & 61 & 24 & 32 & 5 \\
\hline Video conferencing & 10 & 4 & 0 & 6 \\
\hline Diary/calendar & 60 & 23 & 20 & 17 \\
\hline Sound recording & 40 & 4 & 12 & 3 \\
\hline $\begin{array}{l}\text { Access to pocket software } \\
\text { Word, Excel (for example) }\end{array}$ & 5 & 2 & 0 & 24 \\
\hline Web Access & 64 & 8 & 32 & 0 \\
\hline 3G capability & 11 & 5 & 6 & 21 \\
\hline Bluetooth & 57 & 11 & 25 & 8 \\
\hline Wireless capability (WiFi) & 16 & 5 & 3 & 25 \\
\hline Infra Red & 37 & 6 & 6 & 8 \\
\hline $\begin{array}{l}\text { Synchronisation with personal } \\
\text { computer }\end{array}$ & 21 & 5 & 8 & \\
\hline
\end{tabular}

The on-line survey provided detailed information regarding the number of primary PGCE students that possessed mobile phones and the features which were available to them. In addition to this, the survey provided relevant space for students to provide indication of the features they used most frequently, least frequently or not at all. Students were also prompted to provide qualitative data regarding the reasons for not using features available to them.

The students who responded to this survey all indicated that they used text messaging most often however all of the additional features listed above were 
used less frequently by the cohort of students as a whole. Some students provided additional information and indicated that although they could not select the 'never used' category they had only used some of the features listed once or twice during the time they had had the mobile phone. Features such as video capture, diary/calendar and the World Wide Web were highlighted by the students as being rarely used. Explanations offered for not using features available to them appeared to fall into one of five categories with the first being the most frequent response and the fifth being the least frequent.

1. Do not know how to.

2. Never needed to.

3. Prefer to use alternative devices/resources (e.g. digital camera, paper-based diary).

4. Too expensive (this related entirely to accessing of the World Wide Web).

5. Easier to use personal computer (examples given included World Wide Web access, use of e-mail, drafting documents).

Service providers covered a wide range with students indicating little preference between them. Providers such as Three and T-mobile appeared to be more popular but there was little to indicate that one provider was more likely to be selected in preference to another. In terms of the make of mobile phone used, the Symbian operating system appeared to dominate the field with Nokia, Motorola and Sony Ericsson comprising just over eighty percent of the student mobile phones.

Although this survey provides a limited overview regarding student access and use of mobile phones, it does appear to indicate that there are wider issues related to the successful integration of such technology within the teaching and learning environment. For example, students may need support in how their smartphones may be used to access, share and capture data. Consideration needs to be given to the costs involved in using smartphones to access data. If costs are prohibitive to a student a new digital divide may emerge where only those students with the necessary funds may actively engage with materials presented through the medium of the smartphone.

In terms of the intended project, should the tutors purchase exactly the same type of phone and select the same service provider compatibility and interoperability issues would effectively be eliminated. However it was decided that each member of the group should select their own preferred phone and provider in order to reflect, on a much smaller scale, the range and diversity of models which students had access to. Such decisions are pertinent to the realworld experience of the students and the resulting package; both phone and service would have impact upon what and how individuals access, exchange and capture data.

\section{Mobile phone technology and its potential to support teaching and learning in initial teacher education}

Digital communication systems provide opportunities for individuals to create and participate in learning communities where common interests may be shared and discussed regardless of time or distance. 
Emphasis within initial teacher education is placed upon reflective practice where students are encouraged to consider their actions and identify ways in which they may develop and progress. Schon [2] introduced the notion of 'reflection in action' where the teacher effectively considers, evaluates and develops their understanding and knowledge as a result of analysing their practice in real time. Whilst on school experience students are encouraged to engage in the documentation of reflective practice through narrative presented within their school placement file and through discussions with their schoolbased mentor and university liaison tutor. Such discussions are elevated to a wider audience through the use of discussion boards accessed through the university's online learning environment. Here the whole cohort and university tutors may engage in discussions surrounding professional issues within the context of primary education. The role of the teacher within this context is clearly that of facilitator; an individual who engages in discussion as part of a learning team. Questioning, guiding and encouraging participation of students in addition to designing appropriate learning opportunities which enable learners to collaborate and interact are part of the changing role of teacher and student within the online environment [12].

With the potential to capture, share and receive video and still pictures using smartphones the range and variety of potential resource material may increase to include data-rich images. Such devices offer immediacy and flexibility to the process of data capture and communication with others. One student has already begun to use their smartphone to document wall displays they have created whilst on school placement and has communicated such images to other students on the PGCE programme in order to gain useful feedback. It has also been possible to capture short video clips which provide visual data regarding management and organisation of teaching space. Further potential lies within the facility for mobile video-conferencing. According to Nesta Futurelab third generation $(3 \mathrm{G})$ phones can be 'interactive, providing the opportunity for broadcast, transmission and interactive video-conferencing' [11]. Individuals within the widely dispersed teaching community may report from a particular location either to another smartphone or to a desktop computer. This, in turn, may be projected onto a large screen allowing interactions between the student cohort and teacher colleagues within schools. Such opportunities capitalise upon the immediacy, mobility and media-rich data capture facilities of the smartphone. Similarly, opportunities for tutor observation and feedback on students' teaching practice may also be supported through virtual visits to the classroom or through the sharing of pre-recorded video. Brandt and Hillgren [14] describe how selfproduced videos were shared between staff working in an intensive care unit. The videos were originally produced using digital video recorders and then accessed through handheld computers equipped with barcode readers in order to provide easy access to the video library. In this instance the mobility of the handheld mobile computers and the nature of the media displayed provided immediate and data-rich opportunities for situated learning where one colleague would provide guidance videos for their colleagues. Such activity resonates with Schon's [2] notion that professional knowledge is embedded within shared 
communities of practice which may be implicit rather than explicit and therefore difficult if not impossible to express verbally. By using video, aspects of practice which are tacit may be evidenced and communicated through visual means.

Consideration may therefore be given with regards peer-to-peer learning with students recording and transferring video clips in small groups or uploading it to a designated site. Whilst it would be possible to include images within messages posted to the online discussion board or within the content areas created by the tutors the size of the smartphone screen is still significantly smaller than a personal computer screen making navigation through the managed learning environment a more laborious affair. Some websites now offer mobile versions which provide pages that are more easily navigated and viewed on the small screen. Additionally, some companies have emerged which offer access and distribution of video content to $3 \mathrm{G}$ handsets. For example MXtelecom [13] utilise the soon to be launched Video Short Codes and offer to deliver live or recorded video content straight to the end user's $3 \mathrm{G}$ handset.

The technologies associated with mobile devices such as $3 \mathrm{G}$ smartphones are fast changing and provide increasing opportunity for individuals to access, exchange and capture media rich data in a flexible and relatively instantaneous manner. The challenge which faces Initial Teacher Education and indeed the professionality of teachers is how such technologies may be utilised most effectively and how advancement in technologies and professional development may be influenced to support the teacher as professional.

\section{Conclusion}

Hargreaves (15) suggests that the conventional notion of teacher professionalism as knowledge-based with specialist expertise is, in more recent times, giving way to one which requires 'the exercise of discretionary judgement within conditions of unavoidable and perpetual uncertainty'. Hargreaves [16] describes this time of unprecedented change as the 'postmodern age' driven by globalized market forces and the 'electronic and digital revolution in communications leading to instantaneous, globalized availability of information and entertainment.' Both student teachers, qualified teachers and teacher educators would benefit from the development of learning communities which utilise technologies which are widely available and capable of capturing data which enhances reflective practice. Through such processes, teaching and learning may be genuinely enhanced and a knowledge base generated which is both rigorous and integrated with practice.

It appears that there is much to be gained from the immediacy and flexibility offered by mobile communications devices such as $3 \mathrm{G}$ smartphones however there are also wider issues which need to be addressed in order to make this a purposeful experience for students, tutors and teachers. As indicated earlier, some incompatibilities between different operating systems would require the development of solutions which facilitate the transfer and access of media files. Although the university's online learning environment provides opportunity for files to be shared and discussions generated there appears to be a developing 
tension between the relatively static institutional system and the dynamic, portable provision afforded by mobile communications technologies. As teacher educators we need to engage with the potential of such systems and technologies to support professional development and the notion of communities of reflective practice.

\section{References}

[1] Preece, J., Online Communities; Designing Usability, Supporting Sociability, John Wiley and Sons, Chichester, pp 54-63, 2000.

[2] Schon, D, A., The Reflective Practitioner; How professionals think in action. Basic Books, New York, pp. 3-20, 1983.

[3] Castells, M., (ed) The Network Society: A Cross-Cultural perspective. Edward Elgar: Cheltenham, pp. 7-22, 2004.

[4] Hargreaves, D., Creative Professionalism; The role of teachers in the knowledge society. www.demos.co.uk 1998.

[5] Department for Education and Skills, Five Year Strategy for Children and Learners. The Stationary Office, London, p. 80, 2004.

[6] Moore, R., Education and Society; Issues and explanations in the sociology of education. Polity Press, Cambridge, pp 156-157, 2004.

[7] Hoyle, E., Professionality, professionalism and control in teaching. London Educational Review 3(2) pp 13-19, 1974.

[8] Livingston, A., Smartphones and other mobile devices: the Swiss army knives of the $21^{\text {st }}$ century. Educause Quarterly, 2, pp. 48-52, 2004.

[9] Anderson, P. \& Blackwood, A., Mobile and PDA technologies and their future use in education. JISC Technology and Standards Watch www.jisc.ac.uk/iploaded documents/ACF11AE.doc November 2004.

[10] Anderson, P., Mobile and PDA Technologies: Looking around the corner. JISC Technology and Standards Watch www.jisc.ac.uk/uploaded_documents/jisctsw_05_04.doc October 2005.

[11] Nesta Futurelab Innovations Workshops, Future Phones, www.nestafuturelab.org/research/innovations/phones_insight_paper_01.ht m June 2005.

[12] Ryan, S, Scott, B, Freeman, H and Patel, D., The Virtual University; The Internet and Resource-Based Learning, Kogan Page, London, p.112, 2000.

[13] MXtelecom, MX Telecom Video Gateway Service, www.mxtelecom.com/uk/video.

[14] Brandt, E and Hillgren, P., in Attewell, J and Savill-Smith, C., (ed) Learning with Mobile Devices: research and development, Learning and Skills Development Agency, London, pp 27-34, 2004.

[15] Hargreaves, A., Changing Teachers, Changing Times: teachers' work and culture in the postmodern age, Cassell, London, p.19, 1994.

[16] Hargreaves, A., Four Ages of Professionalism and Professional Learning, Teachers and Teaching: History and Practice, 6(2), pp151-182, 2000. 